\title{
功能对等视角下的俄语成语翻译方法研究
}

\author{
玛伊热・艾合麦提 \\ 喀什大学 \\ DOI:10.32629/er.v3i9.3198
}

\begin{abstract}
[摘 要] 世界上的各种自然语言中都有成语存在, 它们在人们的言语交际中发挥着非常重要的作用,因 为成语一般都“言简意赅,富有形象性,使用成语可增加说话和写作的表现力。”成语的形成有着永久的 历史, 是经过人们长期以来的无数次使用才在语言系统中逐渐积淀下来的, 因此, 对成语的翻译不能脱离 开它赖以产生的历史环境与文化背景。作为翻译者, 我对俄语成语的翻译方法以及俄语成语在人们的言 语交际过程中的各种功能进行分析和研究。
\end{abstract}

[关键词] 俄语成语; 语体研究; 功能对等; 翻译策略

中图分类号: G623.35 文献标识码: A

\section{1 俄语成语的概述}

成语作为一种特殊的语言单位, 在 言语交际活动中发挥着重要的作用。德 国哲学家E. 弗洛姆曾经指出: “进行任何 讨论的先决条件都是澄清定义, ”对俄语 成语翻译的研究也不例外。为了更加全 面, 深入的分析和研究俄语成语的翻译, 首先, 必须得了解清楚 “什么是成语? ” 这个关键性问题。对于成语的概念, 不同 的语言学者们有不同的看法, 如: 一方面, 成语是介于词、词组和句子之间的一种 语言单位。另一方面, 成语是民间语言的 精华, 它集中反映着一个民族的风俗习 惯、历史发展、价值观念以及该民族对 客观世界的认识。除此之外, 成语以其意 义简洁、结构严谨、形象生动等特点在 人们的交际过程中发挥着重要的作用和 功能。

在俄语中, ф $\mathrm{p}$ а 3 е о л о Ги я 这一术语源自希腊语的phrasis ( o б о р о т, в ыр а жен и е - 短语, 用语) 和 $\log O S$ ( П О н я Т и е, у ч е н и е - - 概念, 学说), 直义为 短语学 ( у ч е н и е о б о б о p о т а X р е ч и)。在俄罗斯语言学 史上, 成语曾有过不同的名称, 如在十八 世纪 M. В. Л О M O $\mathrm{H} O \mathrm{O}$ ○ $\mathrm{O}$ 曾将其 称为 $\phi$ р а $з$ е с ы, я, и д и о м а т и з мы 等等, 在
其他语言学家的著述中, 成语又被称为 х о д я и е вы р а жен и я, сли тны е р ечи, обо о о ты р е чи, ид ио мы, и д и о м а т и з мы, У с т о й ч и в ы е вы р а жения, не и з м е н н ы е с ло в о с о че т а ни я, фр а з е о лог и ч е с к и й $о$ б о р о т等等。

原苏联学者 В. П. Ж у к $о$ в 认 为: 成语是在言语中可以复现的按并列 关系或从属关系构成的词的组合 (具述 谓性或无述谓性), 它们具有完整的意义 (在少数情况下具有部分完整的意义), 可与其它词搭配。他举例说明, 像 н и р ы б а н и м я с о (不三不四, 四 不像), н и х о л о д н О a $\mathrm{p} \kappa$ O (不冷不热); Г н у T b $\mathrm{C}$ П и н у (辛苦操劳, 受苦受累), с т p e ля т ь и з п У шк и п о в о p o б ь я M (杀鸡用牛刀, 小题大 做); $\mathrm{\kappa}$ a $\mathrm{\kappa} \quad \sigma \quad \mathrm{e} 3 \mathrm{p} \mathrm{y} \mathrm{\kappa}$ (就像失去 双手一样, 毫无办法, 什么也不能做), $\mathrm{k}$ а к й (沮丧的样子, 愁眉苦脸, 闷闪不乐); $\mathrm{H} \quad \mathrm{a} \quad \mathrm{H} O \mathrm{C}^{\circ} \mathrm{y}$ (快到, 马上就要到..... 的时间), н е 3 а г о р а м и (很 快, 不久); х л е б - с о ль (饭食, 宴席; 款待, 盛情招待), р у к и н $\mathrm{e}$

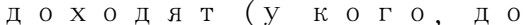
ч $\mathrm{e} \Gamma \mathrm{O}$ ) (顾不上, 没有功夫, 来不及) 等都属于成语。

俄罗斯成语学家 A. И. М О Л О Т K O B 曾经指出: “在俄语学界, 对于什 么是成语, 或者说什么是语言的成语性 单位 ( $\Phi$ p a 3 e о л о Г и ч е с а я е дин иц а я $з$ ы ка) 这 一问题, 尚没有一个统一的认识, 因而对 成语所应包括的范围也就没有一致的观 点。” 其实, 这一现象并非仅仅存在于俄 语学界, 就是在世界语言学界, 众多学者 对成语的定义也并没有一个统一的看 法。随着社会的发展, 语言也不断的会更 新, 随之而来也会出现新的成语。成语的 涵义通常并不等于所由组成的各个词词 义的总和, 对此进行翻译的时候要采用 适当的翻译方法, 不能直接翻译成另一 种语言, 因此, 成语有结构定型、语义统 一的特征。

\section{2 俄语成语的语体特点}

成语作为一种表达效果的语言手段, 虽然具有生动, 形象, 简练等特点, 同时 能使表达效果达到最佳, 但是成语也不 能乱用。20世纪50年代以来在原苏联形 成的功能修辞学把语言分成两大语体: 书卷语体和谈话语体, 其中书卷语体还 包括科学语体、文学艺术语体、正式公 文语体、政论语体等四种语体。 
俄语成语中语体分布不够均匀, 俗 语成语较多, 书卷语体成语数量较少。如 成语 В а в и л О н с к а я бл у д н и ц а (放荡的女人), в з л е т е т ь н а $Г$ е ли и к он (成为诗

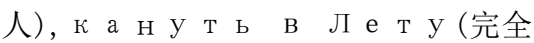
被人遗忘, 永远消逝), п е р е й т и р у б и к о н (跨出决定性的一步, 闯 过有重要意义的一关), $\mathrm{T}$ е л е ц (金钱, 金钱的势力) 等成语 均注为 “ “ ки и жи.” (书卷语体)。

书卷语体, 如前所述, 包括科学语 体、文学艺术语体、正式公文语体和政 论语体。书卷语体的特点是准确、严肃、 庄重, 句式结构完整, 层次分明, 逻辑性 强。例如:

С л о в о к》 пр и о б р е л о п ра в о Г р а жд а н с т в а н е т о л ь к о в п о ли и и ч е с к о й ж и з н и $\mathrm{P}$ о с с и и , н О и В О В с е й 3 а Г р а н и ч н о й п $\mathrm{p}$ e $\mathrm{c}$ c e e, л е д и т 3 а р а 3 в и ти е м с о б ы ти й в о бщи и ч p т a x. (《列宁全集》第27卷, 102页)

译文: “布尔什维克”这个词不仅在 俄国政治生活中, 而且在一切注视俄国 各方面事件发展的外国报刊上都得到了 公认。

在例句中成语 о п р а в о Г р а жд а н с т в $\mathrm{a}$ (得到公认, 广为流传) 是书卷语体, 用 于政论文中非常得体, 一般口语中用 п о л у ч и т ь о бщ е е п р и з н а н и е 或по л уч и ть ши р е н и е 就可以表达 “得到公认” 这个 意思了。

文学作品中也常常使用书卷语体成 语, 如:

(1) А н а род-то на д н и м н а с меялся: - Поделом т е б е, с т а ры й н е в е жа! В п р е д т е бе, н е в е жа, на ука: Наука: Не сади и ь н е в с в о и с а н и !

译文: 人们都嘲笑他: “老糊涂, 真 是活该! 这是给你点儿教训, 往后你得安 守本分!”

分析：在例句中成语 $\mathrm{H}$ e $\mathrm{c}$ а д и с ь н е в С в о и с а н и (要安分守己; 不是自己的事情不要去 管; [旧]不要试图和属于更高层社会的 人去比高低) 是书卷语体, 用于文学作品 当中非常得体,一般口语中用 $\mathrm{H}$ e c У 或 $\mathrm{H}$ е в 3 e t e 也可以表达 “要安分守己” 这 个意思了。

(2) Жил был за т ридевять з е м е ль, в т р и д ц а т о м к н я ж е с т в е о т с е л ь, В е ли к и й и пр е муд ры й ц а р ь. (М. Ю. Л е р м О т о о $)$.

译文: 从前在那遥远的地方, 在第 30 个公爵领地, 有一个伟大而聪明的国王。

分析：在此例句中的成语 “Жи л б ы л 3 а e м е л ь” 表示 (从前在那遥远的地 方), 也属于书卷语体。

与书卷语体相对立的语体是谈话语 体。谈话语体的成语修辞上具有很强的 表现力和各种感情评价色彩(如讯讽、轻 荋、戏谑等)。如: B e ш а T b H O с ы (垂头丧气), $к$ у д а $\mathrm{M} \mathrm{a} к$ a т е л я т н е Г о н я л (到很远), жд д $а$ т ь н е до жд а т ь с я (焦急地等待), м ы ш ь н a п у (生……的气), и г р а т ь м е д и ю (做戏, 假装; 蒙骗), к а к В В о д У 海, 无影无踪, 不翼而飞), л е 3 T и з к О жи и в О $\mathrm{H}$ (拼命, 特别卖力 气), м е д в е жи й у гол (荒僻 的地方, 穷乡僻壤), н а $б$ и т $\mathrm{b}$ p y K y (学会本领, 获得技能), O б B e c т и в о к р у г п а л ь ц а (愚 弄, 巧妙地欺骗), п а л е ц л е ц н е у д а р и т ь (手指头 都不动一下, 不尽一点力, 不采取任何行 动), $\mathrm{c} \Gamma \mathrm{p}$ e $\mathrm{x} о \mathrm{O} \quad \Pi$ п п о
（勉勉强强, 马马虎虎; 用不正当手段, 不光明否落地), $\mathrm{T}$ a $\mathrm{H}$ ц $\mathrm{e} \mathrm{B} \mathrm{a} \mathrm{T} \mathrm{b}$ о т п е ч к и (按老一套办, 照老一 套开始), х $л$ л $о$ о м и (闭口不言, 不知说什么; 莫名其妙, 不知所措), ч у ж и м и р у к а м и ж а 别人的劳动成果, 损人利已, 坐享其成), ш и в о $\mathrm{T}$ (颠倒, 完全相反; 乱套, 反常, 不对头), я б л о к у н е Г д е у п а с т ь (非常拥挤, 水泄不通; 满满登登) 等。

\section{3 俄语成语的翻译策略}

翻译已经不再仅仅看作是语言符号 的转换, 而是一种文化转换的模式。国际 知名翻译理论学者、比较文学家和诗人 苏珊 - 巴斯内特文化功能对等观点提出 了三层含义:

首先, 在翻译过程中必须考虑语言 背后的文化因素, 因为任何一种语言与 载荷它的社会文化都具有不可分割的联 系, 其次, “对等equivalence” 绝不意味 着 “同一sameness”。而是有着不同的层 次, 如词汇对等、语法结构对等、功能对 等, 如果把语言背后的文化因素纳入关 照范围, 功能对等为权宜之计; 第三, 要 使译文在目标语文化中发挥的功能与原 文在原文化中发挥的功能相同, 翻译过 程中必须进行文化转换。

在从事俄语成语翻译工作时, 避免 发生不必要的误译, 造成文化上的疏漏 或误导, 不仅需要了解俄罗斯国家的文 化背景, 需要充分关注中俄两个民族的 文化异同, 应尽可能调动文化知识储备, 还得掌握好相应的翻译方法, 从而把成 语中所蕴含的俄罗斯文化真实、准确、 自然地传递给读者。笔者将俄语成语的 翻译原则从以下三个方面去分析。

\section{1 引用法}

在翻译文化器物、谚语熟语等这一 类内容时, 可以采取 “引用” 的方法, 既 丰富了本民族的语言, 也原原本本地向 读者展示了源语言的精彩。例如:

(1) Н и ки т а, а по ч е м у с р а 
О м У Ч Т О, Д р у Г м О Й, Ч Т о Т о Ч е Ш ь П О Н Я Т о ч У Ю П о с л о в и ц У : С е м ь p а з п р и м е ь, а О ди н

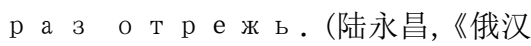
文学翻译概论》）

译文: 尼基塔, 你为什么不想立即给 我们出主意呢? 这是在于, 我的朋友, 是 在于你怎么都不想理解咱们的俄罗斯一 个非常重要的谚语: 七次量衣一次裁。

分析：这段话中 $\mathrm{C}$ e $\mathrm{m}$ b $\mathrm{p}$ a 3 п р и м е р , а оди н o $\mathrm{T}$ p e ж $\mathrm{b}$ 意思是在裁剪衣服之前要 先测量七次, 这是俄语中随着社会发展 而在民族中世代流传下来的浐语, 反映 出俄罗斯民族的习俗。上段文字的翻译, 通过引用俄罗斯人用量衣与剪裁这种表 达方式, 说明做事情之前要经过仔细的 思考, 类似于汉语谚语 “三思而后行”。 翻译的时候不直接按照汉语浐语翻译, 而是原原本本引用俄语浐语, 可以使读 者体会到俄罗斯社会的风俗。

(2) Его стали успокаивать, д а ж е п о с м е и в а л и с ь н а д е го и с п у Г о м, н о с к а 3 а л: “- А х, Г О а, пуганая ворона ку с та б о и т с я. Е с ли б ы В а м п р ишл о с ь и с п ы т а т ь т о, Ч Т о я и с п Ы Т а л, т а к в ы бы те п е р ь н е с м е я л и с ь." ”

译文: 大家开始安慰他, 甚至都笑他 如此惊慌失措, 不过他说: “啊, 先生们, 受惊的乌鸦连见了灌木从都怕！要是你 们受过我承受过的恐惧, 现在就不会笑 我了。”

这里 a $\kappa$ у “受惊的乌鸦连灌木从都害怕”, 相似于 中文浐语 “一朝被蛇咬, 十年怕井绳”。 这涉及俄罗斯国情文化知识, 俄罗斯森 林覆盖面积极为广阔, 而乌鸦则是俄罗 斯森林中最常见的一种鸟类, 所以这里
的中文译文很好地再现了不同民族间在 表达同一情感时表达方式的不同。

\section{2 阐释法}

由于中俄两国的文化博大精深, 它 们在历史文化传统、风俗习惯、民族心 理、思维方式和价值观念等方面存在着 较大差异, 不具备相应文化背景知识储 备的读者常常在理解俄语成语时常常会 产生困难、偏差甚至是错误, 很多言语习 惯放在特定的文化中很易于被人们所理 解, 但换到另一个文化环境中就会让人 感觉莫名其妙、难以理解。这就需要我 们对成语加以相应的注解, 特别是一些 特定文化背景的注释, 使得读者可以从 中收获一定的背景知识, 从而帮助读者 更好地理解俄语成语的深刻内涵和文化 特色。

严复曾说过: “西文句中名物字, 多 随举随释, 如文中之旁支, 后乃遥接前文, 足意成句。故西文句法, 少者二三字, 多 者数十言。” (《天演论 - 译例言》) 因此 当翻译这类词语时, 可以采用 “阐释” 的 办法来解决这类问题。

(1) С д е л а л о с ь в н е 3 а пн о е, гл у бо к о е м о л ч а н и е ; В о т “ т и х и й а нг е л пр о л е те л,, $\cdots$ п о д у м али в с е. ( Т урге н е в Ив а н С е рг е е в ич. 《Д в о р я н С $0 \gg)$

【原译】: 忽然大家全都沉默了, “一 个安静的天使飞过去了” 所有人都这么 想。

分析：译文对 Т и Х и й а Н Г е л 译。对俄罗斯文化没有足够了解的读者 很难理解 “大家完全沉默” 和 “天使飞 走”之间有什么联系, 这涉及到俄罗斯人 的文化, 就需要译者在原译文的基础上 对此国情知识进行补充, 以方便读者理 解原文。

【改译】: 忽然大家全都沉默了, “一 个安静的天使飞过去了”.......所有人都 这么想。(注: 俄罗斯人民间说法认为若 是一群人突然集体沉默不语, 一定是此
时有一个天使正从天空飞过。）

(2) 3 д р а в с т в у й, - п о д у м а л А р к а д и й ..... - $\mathrm{P}$ а $з$ в е мы н е в и д е л и с ь с е Г о д н я? (И. С. Т у р г е н е в 《O т цы и д е т и 》)

【原译】: “你好” 阿尔卡季暗想, “难道今天我们是第一次见面吗?”

分析：这两句话翻译成中文后看上 去并没有特别之处, 反而会令读者不明 白为什么用 “暗想”一词来表达主人公 的疑虑, 主人公的疑虑何在。这就涉及俄 罗斯文化生活理念方面的问题。俄罗斯 人之间见面, 通常只在一天内第一次见 面时用 问候对方, 这一天内再次见面通常说: д о б р ы й д е н ь, д о б р ы й в е ч е р, з д р а в с т в у й ( $\mathrm{t}$ е $)$ е щ ё р а з, мы уж е в и д е л и с ь 等, 所以主人公才会 有如此疑虑, 因此在翻译时需要再加上 一段解释说明。

【改译】“你好”阿尔卡季暗想, “难 道今儿我们是第一次见面吗?”（注：只 有在一天之内双方第一次见面时采用 зд р а в с т в у й ( т e) 彼此问 候。

在语言中 $\mathrm{x} л \mathrm{e} \sigma-\mathrm{c}$ о л $\mathrm{b}$ 已经 成为一个不可分割的词义融合的整体。 人们常说: $\mathrm{x} \pi \mathrm{e} \sigma-\mathrm{c}$ о $\pi$ в $\mathrm{B}$ a м! (祝您胃口好!) С п а с и б о 3 а х л е б-с ол в ! (谢谢您的盛情 款待!) Х л е б-с ол ь е ш ь, а п р а в д у р е ж ь. (受人款待, 应 直言不讳。) Б е 3 х л е 6 a $-c$ о л и о б е д а т ь н е с а д и т с я. (非请莫入席) 等等。 $\mathrm{x} \pi \mathrm{e} \sigma-\mathrm{c}$ о л ь 的直译为 “面包和盐”, 为了让 中国读者正确的明白“ ь ”在俄罗斯文化中表达的含义, 需要加 以注释。

3. 3 替代法

3. 3. 1 翻译策略之 “替代” 法

由于存在的文化背景不同, 许多词 语在翻译时不能按照源语言逐词翻译, 
基于读者不同的文化背景、理解水平， 可以采取 “替代” 的方法, 找取意义相同 的词汇进行翻译, 以此帮助读者正确理 解原文的涵义。在采用 “替代” 的方法 翻译时, 要求译者有深厚的文学功底, 只 有在足够了解本国文化和外国文化的情 况下才能准确找到相对应替代的内容。

有时, 俄语描述的一件事直译过来 后可以用汉语浐语或熟语来替代, 例如:

原文: Н е б уд у т люди д р у г н а д р уг а к и в а т ь : “ты, мол, э то с д е л а й! ”- “Н е т, ты!” А т о у л о п о по с ло в ице. “Д е с я т е р о м е р т в е ц а х о р о нили, ме р тв ец не з а р ы ты ы О с та л с я." ( А. Ч е й в или, 《Л е ло》)

译文: 大家就不会相互推诿责任, 一个说: “这件事你去做!”一个说: “不, 你去做!”不然的话, 咱们常常会应了那 句老话: “三个和尚没水吃”。(叶冬心译)

分析: Д е с я т е p о м е p т в е ц а х о р о ни ли, м е т в е ц н е з а р ы ты м о с т а л с я 直译为 “十个人埋一个死人, 最终也没埋成。”这是俄罗斯人的一句浐 语, 没有俄语文化背景的读者理解起来 比较困难, 所以译者应选择中文意思对 等的谚语来替代原句, 即“一个和尚挑水
吃, 两个和尚抬水吃, 三个和尚没水吃。” 而英语的译文则是 “ One boy is a boy, two boys half a? boy, three boys no boy.”

不同的国家, 不同的民族有着不同 的文化, 风俗习惯, 而俄语成语是俄罗斯 语言文化的精粹, 彰显了俄语的独特魅 力, 承载着丰富多彩的俄罗斯民族文化, 涉及到政治、经济、民俗、哲学、生活、 价值观念等方方面面。因此, 在将俄语成 语进行翻译的过程中, 译者除了要注意 语言本身的对译, 还要注意藏在语言背 后的丰富多彩的文化内涵的阐释和对 译。如果忽视了两种语言之间的文化差 异, 就很容易产生偏误甚至是错误, 造成 翻的失败。

综上所述, 俄语成语的翻译, 最重 要的是要做到 “忠实”, 即忠实于原文 的意义, 忠实于原文的风格和文化特 色。与此同时, 译者也需要考虑受众是 否能够接受译本。在此基础上, 译者也 要灵活变通, 充分发挥自己的创造性, 使俄语成语的汉译真正地做到 “信、 达、雅”。

\section{4 结语}

成语作为民族文化宝库中的璀璨明 珠, 它全面地体现了人民的智慧、民族的 历史、社会制度、世界观、哲学思想, 以及人类认识活动的其它成果。因此, 在翻译时也要尽可能表现出这些作用和 特点。以上翻译方法也不是一成不变的,
要根据具体情况进行灵活选择。

俄语成语汉译的成功与否往往和两 种语言的文化因素、译者的文化背景知 识的储备有非常密切的联系, 并受着它 们的影响与制约。好的译文并不一定是 一蹴而就的, 而是经过译者的厚积薄发, 从而提高译文质量。

[参考文献]

[1]丁昕.俄语成语研究 [M].北京:军 事谊文出版社,2001.

[2]黄忠廉, 白文昌.俄汉双向全译实 践教程 [M]. 哈尔滨: 黑龙江大学出版 社,2010.

[3]姜煦.俄语成语翻译策略 [J]. 安 徽文学(下半月),2018(01):62-63.

[4]林娜.俄语成语汉译问题研究[D]. 南京师范大学,2016.

[5]刘光准,黄苏华.俄汉语言文化习 俗探讨 [M]. 北京: 外语教学与研究出版 社,1999.

[6]王秉钦.文化翻译学 [M].天津:南 开大学出版社,1995.

[7]戚雨村, 董达武, 许以理, 等. 语言 学百科词典 $[\mathrm{M}]$. 上海: 上海辞书出版 社,1993.

[8]王加兴.俄语语言与文化六讲 [M].北京:北京大学出版社,2014.

[9]王福祥,吴汉樱.现代俄语功能修 辞学概论[M].北京:外语教学与研究出版 社,2010. 